\title{
Landsat Plays a Key Role in Reducing Hunger on Earth
}

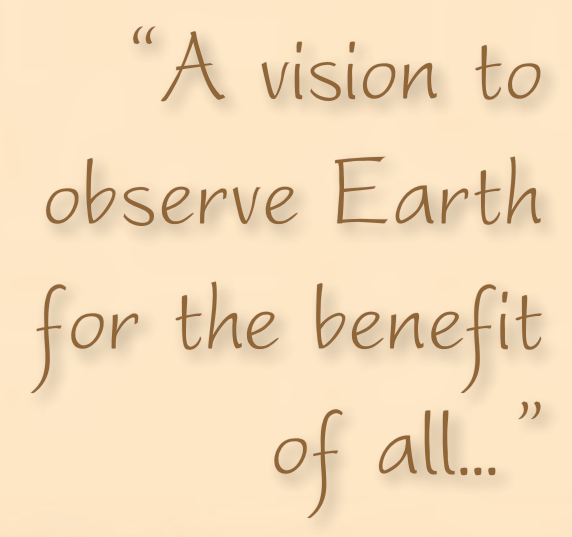

Interior Secretary Stewart Udall, 1966
The United Nations' Department of Economic and Social Affairs predicts 9.7 billion people will sit down every day to the global dinner table by 2050 . If this prediction is correct, the world is going to need more crops, more livestock, and more efficient and sustainable agricultural practices.

The world is going to need Landsat.

The most enduring satellite system covering the Earth, Landsat is already vital to domestic and international food production. Farmers analyze crop health and stress with vegetation indices derived from Landsat. The U.S. Department of Agriculture (USDA) uses remotely sensed data to help formulate reports on crop production, condition, and progress. Even Federal crop insurers tasked with validating claims of hail or drought losses make use of Landsat data. 
Figure 1. Landsat 8 imagery offers an impressive glimpse of agricultural differences along the United States-Mexico border in May 2016. Agricultural growth appears as vibrant green colors in California's Imperial Valley because of irrigation from the Colorado River. In contrast, farming areas are much less green across the border in Mexico, where water access is an issue.

Landsat has been crucial to agriculture since the moment its first satellite launched in July 1972, fulfilling former Interior Secretary Stewart Udall's quest to monitor Earth's natural resources from space. Back then, the world was standing squarely in the midst of an agricultural crisis. The Soviet Union had just signed a 3 -year agreement with the United States to buy millions of tons of wheat and corn at subsidized rates to help offset Soviet crop failures. Lacking a big-picture view of global agricultural output, the United States was caught off guard.

With grain stockpiles dwindling internationally, and domestic prices rising, Landsat could fulfill the need for a more robust agricultural monitoring program in the United States.

Today (2019), satellite data play a key role on multiple food production fronts. Landsat's ability to identify crop types and monitor crop vitality through light reflectance captured by its visible and infrared bands is important to the USDA's crop production and yield reports, according to geographer Dave Johnson with the National Agricultural Statistics Service. Unbiased crop estimates established through ground surveys and validated by Landsat help keep commodity markets from swinging wildly through manipulation, notes Johnson.

Landsat data are used to help produce the Cropland Data Layer (CDL), an annual accounting of agricultural land cover across the continental United States made available after each growing season. The CDL depicts more than 100 unique crop categories. Though not its primary purpose, the CDL has been used to track historical change from, say, wetlands to row crops. It has helped to verify adequate corn resources, or potential for corn crops, for businesses wanting to locate ethanol plants.

The USDA Foreign Agricultural Service has used Landsat for 30 years as part of its overseas crop production monitoring. Remote-sensing data also are part of the Group on Earth Observations Global Agricultural Monitoring Initiative (GEOGLAM). Launched in 2011, the USDA Foreign Agricultural Service and GEOGLAM international partnership uses satellite and ground-based observations to assess growing conditions, crop status, and weather conditions likely to impact global crop production - primarily wheat, maize, rice, and soybeans.

Producers can use satellite imaging to manage risk, notes Jim Hipple, a remote-sensing scientist with USDA's Risk Management Agency. Landsat data can be used to identify areas in fields that need more fertilizer, he says, and also identify weed infestation problems.

When farmers report crop losses from hail, drought, or other disasters, Landsat is an unbiased witness that helps the USDA Risk Management Agency determine whether or not private insurance companies handled claims properly, according to Hipple. Additionally, Landsat satellite data can be used to identify vegetation stress and health, and verify vegetation damage compared to earlier in the growing season, he notes. Because Landsat satellites have been operational for 47 years, Landsat data validate historical patterns for field use, which is important when Hipple's agency reviews claims for events that happened in previous years.

"There are no time-traveling devices," Hipple says. "Landsat is a good surrogate for that."

As a door on the past, Landsat has no equal in satellite history. Landsat's promise for the future remains equally as vital. Life will go on, and more and more people will sit down every day to the world's collective dinner table. When they do, leaders and decision makers, as well as others, are going to need to figure out how to feed them.

They are going to need Landsat.

\section{For additional information, contact:}

Christopher Crawford

Earth Resources Observation and Science (EROS) Center

U.S. Geological Survey

47914 252nd Street

Sioux Falls, SD 57198

605-594-6511

https://www.usgs.gov/centers/eros
ISSN 2327-6916 (print) ISSN 2327-6932 (online) https://doi.org/10.3133/fs20163059 